\title{
Local convergence for a derivative free method of order three under weak conditions
}

\author{
loannis K. Argyros* \\ Department of Mathematical Sciences, \\ Cameron University, \\ Lawton, OK 73505, USA \\ Email: iargyros@cameron.edu \\ *Corresponding author

\section{Santhosh George} \\ Department of Mathematical and Computational Sciences, \\ NIT Karnataka, \\ 575-025, India \\ Email: sgeorge@nitk.ac.in
}

\begin{abstract}
A local convergence analysis for a family of a third-order method in order to approximate a solution of a nonlinear equation is presented in this paper. We use hypotheses only on the first derivative in contrast to earlier studies such as Parhi and Gupta $(2007,2010)$ and Zhu and Wu (2003) using hypotheses only on the first derivative. This way the applicability of these methods is extended under weaker hypotheses. Moreover the radius of convergence and computable error bounds on the distances involved are also given in this study. Numerical examples are also presented in this study.
\end{abstract}

Keywords: Newton's method; bisection method; local convergence; order of convergence.

Reference to this paper should be made as follows: Argyros, I.K. and George, S. (2016) 'Local convergence for a derivative free method of order three under weak conditions', Int. J. Convergence Computing, Vol. 2, No. 1, pp.41-53.

Biographical notes: Ioannis K. Argyros received his BSc from the University of Athens, Greece; and MSc and PhD from the University of Georgia, Athens, Georgia, USA, under the supervision of Dr. Douglas N. Clark. He is currently a Full Professor of Mathematics at Cameron University, Lawton, OK, USA. He has published more than 900 papers and 17 books/monographs in his area of research and computational mathematics. $\mathrm{He}$ is also the editor of 20 peer reviewed research journals in mathematics.

Santhosh George received his $\mathrm{PhD}$ in Mathematics from Goa University, under the supervision of Dr. M.T. Nair. He is a Professor of Mathematics at National Institute of Technology, Karnataka. Six students have completed their PhD under his guidance. He has many international journal and conference papers to his credit. 


\section{Introduction}

In this paper the problem of approximating a locally unique solution $x^{*}$ of equation

$$
F(x)=0,
$$

is analysed, where $F: D \subseteq S \rightarrow S$ is a nonlinear function, $D$ is a convex subset of $S(S=\mathbb{R}$ or $S=\mathbb{C})$. Newton-like methods are widely used for finding solution of equation (1), these methods are usually studied based on: semi-local and local convergence. The semi-local convergence method is based on the information around an initial point, to give conditions ensuring the convergence of the iterative procedure; while the local one is, based on the information around a solution, to find estimates of the radii of convergence balls (Argyros, 2008; Argyros and Hilout, 2010; Ren et al., 2009; Rheinboldt, 1977; Traub, 1964; Ye and Li, 2006; Zhao and Wu, 2008).

Third order methods such as Euler's, Halley's, super Halley's, Chebyshev's (Ahmad et al., 2009; Amat et al., 2008; Argyros, 2008; Argyros and Hilout, 2010; Bruns and Bailey, 1977; Candela and Marquina, 1990a, 1990b; Chun, 1990; Ezquerro and Hernández, 2000, 2005, 2009; Gutiérrez and Hernández, 1998; Ganesh and Joshi, 1991; Hernández, 2001; Hernández and Salanova, 1999; Kantorovich and Akilov, 1982; Parhi and Gupta, 2007, 2010; Parida and Gupta, 2007; Ren et al., 2009; Rheinboldt, 1977; Traub, 1964; Wang et al., 2009, 2011; Ye and Li, 2006; Ye et al., 2007; Zhao and Wu, 2008; Wang and Kou, 2012a, 2012b; Zhu and $\mathrm{Wu}, 2003$ ) require the evaluation of the second derivative $F^{\prime \prime}$ at each step, which in general is very expensive. That is why many authors have used higher order multi-point methods (Ahmad et al., 2009; Amat et al., 2008; Argyros, 2008; Argyros and Hilout, 2010; Bruns and Bailey, 1977; Candela and Marquina, 1990a, 1990b; Chun, 1990; Ezquerro and Hernández, 2000, 2005, 2009; Gutiérrez and Hernández, 1998; Ganesh and Joshi, 1991; Hernández, 2001; Hernández and Salanova, 1999; Kantorovich and Akilov, 1982; Parhi and Gupta, 2007, 2010; Parida and Gupta, 2007; Ren et al., 2009; Rheinboldt, 1977; Traub, 1964; Wang et al., 2009, 2011; Ye and Li, 2006; Ye et al., 2007; Zhao and Wu, 2008; Wang and Kou, 2012a, 2012b; Zhu and $\mathrm{Wu}, 2003)$. In this paper, we present the local convergence of the derivative free method defined for each $n=0,1,2, \ldots$ by

$$
\begin{aligned}
& y_{n}=x_{n}-\alpha F^{\prime}\left(x_{n}\right)^{-1} F\left(x_{n}\right) \\
& x_{n+1}=y_{n}+A_{n} F\left(x_{n}\right),
\end{aligned}
$$

where $x_{0}$ is an initial point, $\alpha \in S(S=\mathbb{R}$ or $S=\mathbb{C})$ is a parameter and $A_{n}=\frac{Q_{n}}{Q_{1}^{n}}$,

$$
\begin{aligned}
Q_{n}= & \frac{\left(F\left(x_{n}\right)-F\left(x_{n}-F\left(x_{n}\right)\right)\right)^{2}}{F\left(x_{n}\right)} \\
& -\frac{F\left(x_{n}-F\left(x_{n}\right)\right)\left[F\left(x_{n}\right)-2 f\left(x_{n}-F\left(x_{n}\right)\right)+F\left(x_{n}-2 F\left(x_{n}\right)\right)\right]}{2 F\left(x_{n}\right)} \\
& -\gamma\left[F\left(x_{n}\right)-F\left(x_{n}-F\left(x_{n}\right)\right)\right] F^{\prime}\left(x_{n}\right), \\
Q_{1}^{n}= & \gamma F^{\prime}\left(x_{n}\right) Q_{0, n},
\end{aligned}
$$




$$
\begin{aligned}
Q_{0, n}= & \left(F\left(x_{n}\right)-F\left(x_{n}-F\left(x_{n}\right)\right)\right)^{2} \\
& -\frac{F\left(x_{n}-F\left(x_{n}\right)\right)\left[F\left(x_{n}\right)-2 F\left(x_{n}-F\left(x_{n}\right)\right)+F\left(x_{n}-2 F\left(x_{n}\right)\right)\right]}{2 F\left(x_{n}\right)},
\end{aligned}
$$

and

$$
\gamma= \begin{cases}\frac{1}{|1-\alpha|}, & \text { if } \alpha \neq 1 \\ 1, & \text { if } \alpha=1 .\end{cases}
$$

If $\alpha=1$ and $S=\mathbb{R}$ method (2) merges with the method studied by Parida and Gupta (2007) (see also $\mathrm{Zhu}$ and $\mathrm{Wu}, 2003$ ). Simply eliminate $y_{n}$ from method (2) to obtain their method

$$
x_{n+1}=x_{n}-\frac{F^{2}\left(x_{n}\right)}{q_{n} F^{2}\left(x_{n}\right)+F\left(x_{n}\right)-F\left(x_{n}-F\left(x_{n}\right)\right)},
$$

where

$$
q_{n}=q\left(x_{n}\right)=-\frac{F\left(x_{n}-F\left(x_{n}\right)\right)\left[F\left(x_{n}\right)-2 F\left(x_{n}-F\left(x_{n}\right)\right)+F\left(x_{n}-2 F\left(x_{n}\right)\right)\right]}{2\left[F\left(x_{n}\right)-F\left(x_{n}-F\left(x_{n}\right)\right)\right] F^{2}\left(x_{n}\right)} .
$$

In this special case method (2) is cubically convergent provided that the third derivative $F^{\prime \prime \prime}$ of function $F$ is bounded in a neighbourhood containing $x^{*}$. The hypothesis on the third derivative limits the applicability of method (2). As a motivational let us define function $f$ on $D=\left[-\frac{1}{2}, \frac{5}{2}\right]$ by

$$
f(x)= \begin{cases}x^{3} \ln x^{2}+x^{5}-x^{4}, & x \neq 0 \\ 0, & x=0\end{cases}
$$

Choose $x^{*}=1$. We have that

$$
\begin{aligned}
& f^{\prime}(x)=3 x^{2} \ln x^{2}+5 x^{4}-4 x^{3}+2 x^{2}, f^{\prime}(1)=3, \\
& f^{\prime \prime}(x)=6 x \ln x^{2}+20 x^{3}-12 x^{2}+10 x \\
& f^{\prime \prime \prime}(x)=6 \ln x^{2}+60 x^{2}-24 x+22 .
\end{aligned}
$$

Then, function $f^{\prime \prime \prime}$ is unbounded on $D$. In the present paper we only use hypotheses on the first Fréchet derivative. This way we expand the applicability of method (2).

The rest of the paper is organised as follows. The local convergence of method (2) is given in Section 2, whereas the numerical examples are given in the concluding Section 3. 


\section{Local convergence analysis}

We present the local convergence analysis of method (2) in this section. Let $\beta>0, L_{0}>0$, $L>0, M_{0}>0, M>1, N \in\left[0, \frac{1}{3}\right)$ and $\alpha \in S$ be given parameters. It is convenient for the local convergence analysis that follows to define some functions and parameters. Define functions $g_{0}$ and $h_{0}$ on the interval $[0,+\infty)$ by:

$$
\begin{aligned}
& g_{0}(t)=\frac{L_{0}}{2}\left(1+3 N^{3}\right) t+N\left(3+M_{0} M\right) \\
& h_{0}(t)=g_{0}(t)-1
\end{aligned}
$$

and parameter $r_{0}$ by

$$
r_{0}=\frac{1\left(1-N\left(3+M_{0} M\right)\right)}{\left(1+3 N^{2}\right) L_{0}}
$$

Suppose that

$$
N\left(3+M_{0} M\right)<1
$$

Then, we have by equation (5) that $0<r_{0}, g_{0}\left(r_{0}\right)=1$ and $0 \leq g_{0}(t)<1$ for each $t \in\left[0, r_{0}\right)$. Moreover, define functions $g_{1}$ and $h_{1}$ on the interval $\left[0, \frac{1}{L_{0}}\right)$ by

$$
\begin{aligned}
& g_{1}(t)=\frac{1}{2\left(1-L_{0} t\right)}(L t+2 M|1-\alpha|) \\
& h_{1}(t)=g_{1}(t)-1
\end{aligned}
$$

and parameters $r_{1}$ by

$$
r_{1}=\frac{2(1-M|1-\alpha|)}{2 L_{0}+L} .
$$

Suppose that

$$
M|1-\alpha|<1 .
$$

Then, we have by equation (7) that $0<r_{1}, g_{1}\left(r_{1}\right)=1$ and $0 \leq g_{1}(t)<1$ for each $t \in\left[0, r_{1}\right)$.

Furthermore, define functions $g_{2}$ and $h_{2}$ on the interval $\left[0, \min \left\{\frac{1}{L_{0}}, r_{0}\right\}\right)$ by

$$
g_{2}(t)=g_{1}(t)+\frac{M_{0}\left(M_{0}^{3}+\frac{L M_{0} N}{4}+\gamma M_{0}^{2}\left(1+L_{0} t\right)\right)}{\gamma\left(1-L_{0} t\right)\left(1-g_{0}(t)\right)}
$$

and

$$
h_{2}(t)=g_{2}(t)-1
$$


Suppose that

$$
\frac{1}{\gamma}\left[M+\frac{M_{0}\left(M_{0}^{3}+\frac{L M_{0} N}{4}+\gamma M_{0}^{2}\right)}{1-N\left(3+M_{0} M\right)}\right]<1 .
$$

We get by equation (8) that $h_{2}(0)<0$ and $h_{2}(t) \rightarrow+\infty$ as $t \rightarrow \min \left\{\frac{1}{L_{0}}, r_{0}\right\}$. It follows from the intermediate value theorem that function $h_{2}$ has zeros in the interval $\left[0, \min \left\{\frac{1}{L_{0}}, r_{0}\right\}\right)$. Denote by $r_{2}$ the smallest such zero. Set

$$
r=\min \left\{r_{1}, r_{2}\right\}
$$

Then, we have that

$$
\begin{aligned}
& 2<4<r_{A}=\frac{2}{2 L_{0}+L}<\frac{1}{L_{0}} \\
& 0 \leq g_{0}(t)<1 \\
& 0 \leq g_{1}(t)<1
\end{aligned}
$$

and

$$
0 \leq g_{2}(t)<1 \text { for each } t \in[0, r) .
$$

Let $U(v, \rho), \bar{U}(v, \rho)$ stand, respectively for the open and closed balls in $S$ with centre $v \in S$ and of radius $\rho>0$. Next, we present the local convergence of method (2) using the preceding notation.

THEOREM 2.1: Let $F: D \subset S \rightarrow S$ be a differentiable function. Suppose that there exist $x^{*} \in D, \beta>0, L_{0}>0, L>0, M_{0}>0, M \geq 1, N \in\left[0, \frac{1}{3}\right), \alpha \in S$ such that for $\gamma$ given by equation (3) and each $x, y \in D$ the following hold equations (5), (7), (8),

$$
\begin{aligned}
& F\left(x^{*}\right)=0, F^{\prime}\left(x^{*}\right) \neq 0, \\
& \left|F^{\prime}\left(x^{*}\right)^{-1}\left(F^{\prime}(x)-F^{\prime}\left(x^{*}\right)\right)\right| \leq L_{0}\left|x-x^{*}\right|, \\
& \left|F^{\prime}\left(x^{*}\right)\left(F^{\prime}(x)-F^{\prime}(y)\right)\right| \leq L|x-y|, \\
& \left|F^{\prime}(x)\right| \leq M_{0}, \\
& \left|F^{\prime}\left(x^{*}\right)^{-1} F^{\prime}(x)\right| \leq M, \\
& \left|I-F^{\prime}(x)\right| \leq N,
\end{aligned}
$$


and

$$
\bar{U}\left(x^{*}, \bar{r}\right) \subseteq D
$$

where

$$
\bar{r}=\max \left\{\left(N+M_{0}\right) r, r\right\}
$$

and $r$ is given by equation (9). Then, the sequence $\left\{x_{n}\right\}$ generated for $x_{0} \in U\left(x^{*}, r\right)-\left\{x^{*}\right\}$ by method (2) is well-defined, remains in $U\left(x^{*}, r\right)$ for each $n=0,1,2, \ldots$ and converges to $x^{*}$. Moreover the following estimates hold

$$
\left|y_{n}-x^{*}\right| \leq g_{1}\left(\left|x_{n}-x^{*}\right|\right)\left|x_{n}-x^{*}\right|<\left|x_{n}-x^{*}\right|<r
$$

and

$$
\left|x_{n+1}-x^{*}\right| \leq g_{2}\left(\left|x_{n}-x^{*}\right|\right)\left|x_{n}-x^{*}\right|<\left|x_{n}-x^{*}\right|,
$$

where ' $g$ ' functions are defined above Theorem 2.1. Furthermore, if there exist $T \in\left[r, 2 / L_{0}\right)$ such that $\bar{U}\left(x^{*}, T\right) \subseteq D$, then the limit point $x^{*}$ is the only solution of equation $F(x)=0$ in $\bar{U}\left(x^{*}, T\right)$.

Proof: We shall show estimates (22) and (23) using mathematical induction. Using the hypothesis $x_{0} \in U\left(x^{*}, r\right)-\left\{x^{*}\right\}$, equation (15) and the definition of $r$, we get that

$$
\left|F^{\prime}\left(x^{*}\right)^{-1}\left(F\left(x_{0}\right)-F^{\prime}\left(x^{*}\right)\right)\right| \leq L_{0}\left|x_{0}-x^{*}\right|<L_{0} r<1 .
$$

It follows from equation (24) and the Banach Lemma on invertible functions (Argyros, 2008; Argyros and Hilout, 2010; Ye et al., 2007; Wang and Kou, 2012a) that, $F^{\prime}\left(x_{0}\right) \neq 0$ and

$$
\left|F^{\prime}\left(x_{0}\right)^{-1} F^{\prime}\left(x^{*}\right)\right| \leq \frac{1}{1-L_{0}\left|x_{0}-x^{*}\right|} .
$$

Hence $y_{0}$ and $x_{1}$ are well-defined by the first substep of method (2) for $n=0$. We can write $F\left(x_{0}\right)=F\left(x_{0}\right)-F\left(x^{*}\right)=\int_{0}^{1} F^{\prime}\left(x^{*}+\theta\left(x_{0}-x^{*}\right)\right)\left(x_{0}-x^{*}\right) d \theta$. Notice that $\left|x^{*}+\theta\left(x_{0}-x^{*}\right)-x^{*}\right|=\theta\left|x_{0}-x^{*}\right| \leq\left|x_{0}-x^{*}\right|<1$. That is $x^{*}+\theta\left(x_{0}-x^{*}\right) \in U\left(x^{*}, r\right)$. Using equation (17) and (18) we have that

$$
\begin{aligned}
& \left|F\left(x_{0}\right)\right| \leq M_{0}\left|x_{0}-x^{*}\right| \\
& \left|F^{\prime}\left(x^{*}\right)^{-1} F\left(x_{0}\right)\right| \leq M\left|x_{0}-x^{*}\right| .
\end{aligned}
$$

In view of the first substep of method (2) for $n=0$, equations (12), (16), (25), (26) and (27) we obtain in turn that 


$$
\begin{aligned}
\left|y_{0}-x^{*}\right| \leq & \left|x_{0}-x^{*}-F^{\prime}\left(x_{0}\right) F\left(x_{0}\right)\right|+|1-\alpha|\left|F^{\prime}\left(x^{*}\right)^{-1} F\left(x_{0}\right)\right| \\
\leq & \left|F^{\prime}\left(x_{0}\right)^{-1} F^{\prime}\left(x^{*}\right)\right|\left|\int_{0}^{1} F^{\prime}\left(x^{*}\right)^{-1}\left(F^{\prime}\left(x^{*}+\theta\left(x_{0}-x^{*}\right)\right)-F^{\prime}\left(x_{0}\right)\right)\left(x_{0}-x^{*}\right) d \theta\right| \\
& +|1-\alpha|\left|F^{\prime}\left(x_{0}\right)^{-1} F^{\prime}\left(x^{*}\right)\right|\left|F^{\prime}\left(x^{*}\right)^{-1} F\left(x_{0}\right)\right| \\
\leq & \frac{L\left|x_{0}-x^{*}\right|^{2}}{2\left(1-L_{0}\left|x_{0}-x^{*}\right|\right)}+\frac{M\left|x_{0}-x^{*}\right|}{1-L_{0}\left|x_{0}-x^{*}\right|} \\
= & g_{1}\left(\left|x_{0}-x^{*}\right|\right)\left|x_{0}-x^{*}\right|<\left|x_{0}-x^{*}\right|<r,
\end{aligned}
$$

which shows equation (22) for $n=0$ and $y_{0} \in U\left(x^{*}, r\right)$. We have by equations (19), (20), (21) and (27) that

$$
\begin{aligned}
\left|x_{0}-2 F\left(x_{0}\right)-x^{*}\right| & =\left|\int_{0}^{1}\left(I-F^{\prime}\left(x^{*}+\theta\left(x_{0}-x^{*}\right)\right)\right)\left(x_{0}-x^{*}\right) d \theta\right| \\
& \leq N\left|x_{0}-x^{*}\right|<\left|x_{0}-x^{*}\right|<r
\end{aligned}
$$

and

$$
\begin{aligned}
\left|x_{0}-F\left(x_{0}\right)-x^{*}\right|= & \left|\int_{0}^{1}\left(I-F^{\prime}\left(x^{*}+\theta\left(x_{0}-x^{*}\right)\right)\right)\left(x_{0}-x^{*}\right) d \theta\right| \\
& +\left|\int_{0}^{1} F^{\prime}\left(x^{*}+\theta\left(x_{0}-x^{*}\right)\right)\left(x_{0}-x^{*}\right) d \theta\right| \\
\leq & \left(N+M_{0}\right)\left|x_{0}-x^{*}\right|<(N+M) r \leq \bar{r} .
\end{aligned}
$$

Hence, $x_{0}-F\left(x_{0}\right) \in U\left(x^{*}, r\right)$ and $x_{0}-2 F\left(x_{0}\right) \in U\left(x^{*}, \bar{r}\right)$. We also have that $F\left(x_{0}-F\left(x_{0}\right) \pm \theta F\left(x_{0}\right)\right) \in D$ and $F\left(x_{0}-F\left(x_{0}\right) \pm 2 \theta F\left(x_{0}\right)\right) \in D$ by the convexity of $D$. Next, we shall show that $Q_{0,0}\left(x_{0}\right) \neq 0$. We can write

$$
\begin{aligned}
Q_{0,0}- & F^{\prime}\left(x^{*}\right)\left(x_{0}-x^{*}\right) \\
= & F\left(x_{0}\right)-3\left(F\left(x_{0}-F\left(x_{0}\right)\right)-F\left(x^{*}-F\left(x^{*}\right)\right)\right) \\
& -F^{\prime}\left(x^{*}\right)\left(x_{0}-F\left(x_{0}\right)-\left(F\left(x^{*}\right)-x^{*}\right)\right) \\
& -3 F^{\prime}\left(x^{*}\right)\left(I-\int_{0}^{1} F^{\prime}\left(x^{*}+\theta\left(x_{0}-x^{*}\right)\right)\left(x_{0}-x^{*}\right)\right)\left(x_{0}-x^{*}\right) \\
& +F\left(x_{0}-F\left(x_{0}\right)\right) \int_{0}^{1} F^{\prime}\left(x_{0}-2 F\left(x_{0}\right)+2 \theta F\left(x_{0}\right)\right) d \theta,
\end{aligned}
$$

since

$$
\begin{aligned}
\frac{1}{2 F\left(x_{0}\right)}\left[F\left(x_{0}\right)-F\left(x_{0}-2 F\left(x_{0}\right)\right)\right] & =\frac{\int_{0}^{1} F^{\prime}\left(x_{0}-2 F\left(x_{0}\right)+2 \theta F\left(x_{0}\right)\right)\left(F\left(x_{0}\right)\right) d \theta}{2 F\left(x_{0}\right)} \\
& =\int_{0}^{1} F^{\prime}\left(x_{0}-2 F\left(x_{0}\right)+2 \theta F\left(x_{0}\right)\right) d \theta
\end{aligned}
$$

and 


$$
\begin{aligned}
F\left(x_{0}-\right. & \left.F\left(x_{0}\right)\right) \\
= & \left(F\left(x_{0}-F\left(x_{0}\right)\right)-F\left(x^{*}-F\left(x^{*}\right)\right)-F^{\prime}\left(x^{*}\right)\left(x_{0}-F\left(x_{0}\right)+F\left(x^{*}\right)-x^{*}\right)\right) \\
& +F^{\prime}\left(x^{*}\right)\left(x_{0}-F\left(x_{0}\right)+F\left(x^{*}\right)-x^{*}\right) .
\end{aligned}
$$

Then, using equations (11), (17), (18), (19), (26), (27) and (29), we obtain in turn since $x_{0} \in x^{*}$ that

$$
\begin{aligned}
&\left|\left(F^{\prime}\left(x^{*}\right)\left(x_{0}-x^{*}\right)\right)^{-1}\left(Q_{0,0}-F^{\prime}\left(x^{*}\right)\left(x_{0}-x^{*}\right)\right)\right| \\
& \leq\left|x_{0}-x^{*}\right|^{-1}\left\{\left|\int_{0}^{1} F^{\prime}\left(x^{*}\right)^{-1}\left(F\left(x^{*}+\theta\left(x_{0}-x^{*}\right)\right)-F^{\prime}\left(x^{*}\right)\right)\left(x_{0}-x^{*}\right) d \theta\right|\right. \\
&+3 \mid \int_{0}^{1} F^{\prime}\left(x^{*}\right)^{-1}\left(F^{\prime}\left(x^{*}-F\left(x^{*}\right)+\theta\left(x_{0}-F\left(x_{0}\right)+F\left(x^{*}\right)-x^{*}\right)\right)\right. \\
&\left.-F^{\prime}\left(x^{*}\right)\right) \int_{0}^{1}\left(1-F^{\prime}\left(x^{*}+\theta\left(x_{0}-x^{*}\right)\right)\right)\left(x_{0}-x^{*}\right) d \theta \mid \\
&+3\left|\int_{0}^{1}\left(I-F^{\prime}\left(x^{*}+\theta\left(x_{0}-x^{*}\right)\right)\right)\left(x_{0}-x^{*}\right) d \theta\right| \\
&+\mid \int_{0}^{1} F^{\prime}\left(x^{*}\right)^{-1} F^{\prime}\left(x^{*}+\theta\left(x_{0}-x^{*}-F\left(x_{0}\right)\right)\right) \\
& \times \int_{0}^{1}\left(1-F^{\prime}\left(x^{*}+\theta\left(x_{0}-x^{*}\right)\right)\right)\left(x_{0}-x^{*}\right) d \theta \mid \\
&\left.\times\left|\int_{0}^{1} F^{\prime}\left(x_{0}-2 F\left(x_{0}\right)+2 \theta F\left(x_{0}\right)\right) d \theta\right|\right\} \\
& \leq\left|x_{0}-x^{*}\right|^{-1}\left[\frac{L_{0}}{2}\left|x_{0}-x^{*}\right|^{2}+\frac{3 L_{0}}{2} N^{2}\left|x_{0}-x^{*}\right|^{2}\right. \\
&\left.+3 N\left|x_{0}-x^{*}\right|+M_{0} M N\left|x_{0}-x^{*}\right|\right] \\
&= \frac{L_{0}}{2}\left|x_{0}-x^{*}\right|+\frac{3 L_{0} N^{2}}{2}\left|x_{0}-x^{*}\right|+N\left(3+M_{0} M\right) \\
&= g_{0}\left(\left|x_{0}-x^{*}\right|\right)<1 .
\end{aligned}
$$

It follows from equation (30) that $Q_{0,0}\left(x_{0}\right) \neq 0$ and

$$
\left|Q_{0,0}^{-1} F^{\prime}\left(x^{*}\right)\right| \leq \frac{1}{\left|x_{0}-x^{*}\right|\left(1-g_{0}\left(\left|x_{0}-x^{*}\right|\right)\right)} .
$$

Similarly, we need an estimate on $|Q|$. We have that

$$
\begin{aligned}
\left|\frac{\left(F\left(x_{0}\right)-F\left(x_{0}-F\left(x_{0}\right)\right)\right)^{2}}{F\left(x_{0}\right)}\right| & =\left|F\left(x_{0}\right)\left(\frac{\int_{0}^{1} F^{\prime}\left(x_{0}-F\left(x_{0}\right)+\theta F\left(x_{0}\right)\right) d \theta+\theta F\left(x_{0}\right)}{+\theta F\left(x_{0}\right)}\right)^{2}\right| \\
& =\left|F\left(x_{0}\right)\right|\left|\int_{0}^{1} F^{\prime}\left(x_{0}-F\left(x_{0}\right)+\theta F\left(x_{0}\right)\right) d \theta\right|^{2} \\
& \leq M_{0}^{3}\left|x_{0}-x^{*}\right|
\end{aligned}
$$


We can write

$$
\begin{aligned}
F\left(x_{0}\right) & -2 F\left(x_{0}-F\left(x_{0}\right)\right)+F\left(x_{0}-2 F\left(x_{0}\right)\right) \\
= & {\left[F\left(x_{0}\right)-F\left(x_{0}-F\left(x_{0}\right)\right)\right]+\left[F\left(x_{0}-2 F\left(x_{0}\right)\right)-F\left(x_{0}-F\left(x_{0}\right)\right)\right] } \\
= & \int_{0}^{1}\left[F^{\prime}\left(x_{0}-F\left(x_{0}\right)+\theta F\left(x_{0}\right)\right)-F^{\prime}\left(x_{0}-F\left(x_{0}\right)+\theta\left(-F\left(x_{0}\right)\right)\right)\right] F\left(x_{0}\right) d \theta .
\end{aligned}
$$

Using equations (16) and (33) we have that

$$
\begin{aligned}
& \left|\frac{\int_{0}^{1} F^{\prime}\left(x^{*}\right)^{-1}\left[F^{\prime}\left(x_{0}-F\left(x_{0}\right)+\theta F\left(x_{0}\right)\right)-F^{\prime}\left(x_{0}-F\left(x_{0}\right)+\theta F\left(x_{0}\right)\right)\right] F\left(x_{0}\right) d \theta}{F\left(x_{0}\right)}\right| \\
& \quad \leq \beta L \int_{0}^{1} 2 \theta d \theta=\beta L \\
& \left|F^{\prime}\left(x^{*}\right)^{-1} F\left(x_{0}-\left|F\left(x_{0}\right)\right|\right)\right| \leq M N\left|x_{0}-x^{*}\right|
\end{aligned}
$$

and

$$
\begin{aligned}
& \gamma\left|F\left(x_{0}\right)-F\left(x_{0}-F\left(x_{0}\right)\right)\right|\left|F^{\prime}\left(x^{*}\right)\right|^{-1}\left|\left(F^{\prime}\left(x_{0}\right)-F^{\prime}\left(x^{*}\right)\right)+1\right| \\
& \quad \leq \gamma M_{0}^{2}\left(1+L_{0}\left|x_{0}-x^{*}\right|\right)\left|x_{0}-x^{*}\right|
\end{aligned}
$$

Using the definition of $Q$ and summing up equations (32)-(36) we get in turn that

$$
\left|Q_{0}\right| \leq\left(M_{0}^{3}+\frac{L M_{0} N}{4}+\gamma M_{0}^{2}\left(1+L_{0}\left|x_{0}-x^{*}\right|\right)\right)\left|x_{0}-x^{*}\right| .
$$

Then, using the second substep of method (2) for $n=0$, equations (9), (13), (25), (26), (28) and (37), we get that

$$
\begin{aligned}
\left|x_{1}-x^{*}\right| & \leq\left|y_{0}-x^{*}\right|+\left|A_{0}\right|\left|F\left(x_{0}\right)\right| \\
& \leq g_{1}\left(\left|x_{0}-x^{*}\right|\right)\left|x_{0}-x^{*}\right|+\frac{\left(M_{0}^{3}+\frac{L M_{0} N}{4}+\gamma M_{0}^{2}\left(1+L_{0}\left|x_{0}-x^{*}\right|\right) M_{0}\left|x_{0}-x^{*}\right|\right)}{\gamma\left(1-L_{0}\left|x_{0}-x^{*}\right|\right)\left(1-g_{0}\left(\left|x_{0}-x^{*}\right|\right)\right)} \\
& =g_{2}\left(\left|x_{0}-x^{*}\right|\right)\left|x_{0}-x^{*}\right|<\left|x_{0}-x^{*}\right|<r,
\end{aligned}
$$

which shows equation (23) and $x_{1} \in U\left(x^{*}, \mathrm{r}\right)$. By simply replacing $x_{0}, y_{0}, x_{1}$ by $x_{k}, y_{k}, x_{k+1}$ in the preceding estimates we arrive at estimates (22) and (23). Using the estimate $\left|x_{k+1}-x^{*}\right|<\left|x_{k}-x^{*}\right|<r$, we deduce that $x_{k+1} \in U\left(x^{*}, r\right)$ and $\lim _{k \rightarrow \infty} x_{k}=x^{*}$. To show the uniqueness part, let $B=\int_{0}^{1} F^{\prime}\left(y^{*}+\theta\left(x^{*}-y^{*}\right)\right) d \theta$ for some $y^{*} \in \bar{U}\left(x^{*}, T\right)$ with $F\left(y^{*}\right)=0$. Using equation (15) we get that

$$
\begin{aligned}
\left|F^{\prime}\left(x^{*}\right)^{-1}\left(B-F^{\prime}\left(x^{*}\right)\right)\right| & \leq \int_{0}^{1} L_{0}\left|y^{*}+\theta\left(x^{*}-y^{*}\right)-x^{*}\right| d \theta \\
& \leq L_{0} \int_{0}^{1}(1-\theta)\left|x^{*}-y^{*}\right| d \theta \leq \frac{L_{0}}{2} T<1 .
\end{aligned}
$$


It follows from equation (38) and the Banach Lemma on invertible functions that $B$ is invertible. Finally, from the identity $0=F\left(x^{*}\right)-F \mid\left(y^{*}\right)=B\left(x^{*}-y^{*}\right)$, we deduce that $x^{*}=y^{*}$.

\section{REMARK 2.2:}

1 In view of equation (15) and the estimate

$$
\begin{aligned}
\left\|F^{\prime}\left(x^{*}\right)^{-1} F^{\prime}(x)\right\| & =\left\|F^{\prime}\left(x^{*}\right)^{-1}\left(F^{\prime}(x)-F^{\prime}\left(x^{*}\right)\right)+I\right\| \\
& \leq 1+\left\|F^{\prime}\left(x^{*}\right)^{-1}\left(F^{\prime}(x)-F^{\prime}\left(x^{*}\right)\right)\right\| \\
& \leq 1+L_{0}\left\|x-x^{*}\right\|
\end{aligned}
$$

condition (18) can be dropped and $M$ can be replaced by

$M(t)=1+L_{0} t$.

2 The results obtained here can be used for operators $F$ satisfying autonomous differential equations (Argyros, 2008) of the form

$F^{\prime}(x)=P(F(x))$

where $P$ is a continuous operator. Then, since $\mathrm{F}^{\prime}\left(x^{*}\right)=P\left(F\left(x^{*}\right)\right)=P(0)$, we can apply the results without actually knowing $x^{*}$. For example, let $F(x)=e^{x}-1$. Then, we can choose: $P(x)=x+1$.

3 The radius $r_{A}$ was shown by us to be the convergence radius of Newton's method (Amat et al., 2008; Argyros, 2008; Argyros and Hilout, 2010)

$x_{n+1}=x_{n}-F^{\prime}\left(x_{n}\right)^{-1} F\left(x_{n}\right)$ for each $n=0,2, \ldots$

under the conditions (15) and (16). It follows from the definition of $r$ that the convergence radius $r$ of the method (2) cannot be larger than the convergence radius $r_{A}$ of the second order Newton's method. As already noted in Argyros (2008) and Argyros and Hilout (2010), $r_{A}$ is at least as large as the convergence ball given by Rheinboldt (1977)

$r_{R}=\frac{2}{3 L}$.

In particular, for $L_{0}<L$ we have that

$r_{R}<r$

and

$\frac{r_{R}}{r_{A}} \rightarrow \frac{1}{3}$ as $\frac{L_{0}}{L} \rightarrow 0$

That is our convergence ball $r_{A}$ is at most three times larger than Rheinboldt's. The same value for $r_{R}$ was given by Traub (1964). 
4 It is worth noticing that method (2) is not changing when we use the conditions of Theorem 2.1 instead of the stronger conditions used in (Parhi and Gupta, 2010; Parida and Gupta, 2007; Zhu and Wu, 2003). Moreover, we can compute the computational order of convergence (COC) defined by

$$
\xi=\ln \left(\frac{\left\|x_{n+1}-x^{*}\right\|}{\left\|x_{n}-x^{*}\right\|}\right) / \ln \left(\frac{\left\|x_{n}-x^{*}\right\|}{\left\|x_{n-1}-x^{*}\right\|}\right)
$$

or the approximate computational order of convergence

$$
\xi_{1}=\ln \left(\frac{\left\|x_{n+1}-x_{n}\right\|}{\left\|x_{n}-x_{n-1}\right\|}\right) / \ln \left(\frac{\left\|x_{n}-x_{n-1}\right\|}{\left\|x_{n-1}-x_{n-2}\right\|}\right) .
$$

This way we obtain in practice the order of convergence in a way that avoids the bounds involving estimates using estimates higher than the first Fréchet derivative of operator $F$.

\section{Numerical examples}

We present numerical examples in this section.

EXAMPLE 3.1: Let $D=(-\infty,+\infty)$. Define function $f$ of $D$ by

$$
f(x)=\sin (x) \text {. }
$$

Then we have for $x^{*}=0$ that $L_{0}=L=M=N=M_{0}=1$. For $\alpha=0.5, \gamma=0.95$, the parameters are $r_{1}=0.3333, r_{2}=0.4047, r=0.3333$.

EXAMPLE 3.2: Let $D=[-1,1]$. Define function $f$ of $D$ by

$$
f(x)=e^{x}-1 .
$$

Using equation (42) and $x^{*}=0$, we get that $L_{0}=e-1<L=M=N=M_{0}=e$. For $\alpha=0.8161, \gamma=1.2590$, the parameters are $r_{1}=0.1625, r_{2}=0.3815, r=0.1625$.

\section{References}

Ahmad, F., Hussain, S., Mir, N.A. and Rafiq, A. (2009) 'New sixth order Jarratt method for solving nonlinear equations', Int. J. Appl. Math. Mech., Vol. 5, No. 5, pp.27-35.

Amat, S., Hernández, M.A. and Romero, N. (2008) 'A modified Chebyshev's iterative method with at least sixth order of convergence', Appl. Math. Comput., Vol. 206, No. 1, pp.164-174.

Argyros, I.K. (2008) Convergence and Application of Newton-Type Iterations, Springer, New York.

Argyros, I.K. and Hilout, S. (2010) 'A convergence analysis for directional two-step Newton methods', Numer. Algor., Vol. 55, No. 4, pp.503-528.

Bruns, D.D. and Bailey, J.E. (1977) 'Nonlinear feedback control for operating a non-isothermal CSTR near an unstable steady state', Chem. Eng. Sci., Vol. 32, No. 3, pp.257-264. 
Candela, V. and Marquina, A. (1990a) 'Recurrence relations for rational cubic methods I: the Halley method', Computing, Vol. 44, No. 2, pp.169-184.

Candela, V. and Marquina, A. (1990b) 'Recurrence relations for rational cubic methods II: the Chebyshev method', Computing, Vol. 45, No. 4, pp.355-367.

Chun, C. (1990) 'Some improvements of Jarratt's method with sixth-order convergence', Appl. Math. Comput., Vol. 190, No. 2, pp.1432-1437.

Ezquerro, J.A. and Hernández, M.A. (2000) 'Recurrence relations for Chebyshev-type methods', Appl. Math. Optim., Vol. 41, No. 2, pp.227-236.

Ezquerro, J.A. and Hernández, M.A. (2005) 'On the R-order of the Halley method', J. Math. Anal. Appl., Vol. 303, No. 2, pp.591-601.

Ezquerro, J.A. and Hernández, M.A. (2009) 'New iterations of R-order four with reduced computational cost', BIT Numer. Math., Vol. 49, No. 2, pp.325-342.

Ganesh, M. and Joshi, M.C. (1991) 'Numerical solvability of Hammerstein integral equations of mixed type', IMA J. Numer. Anal., Vol. 11, No. 1, pp.21-31.

Gutiérrez, J.M. and Hernández, M.A. (1998) 'Recurrence relations for the super-Halley method', Computers Math. Applic., Vol. 36, No. 7, pp.1-8.

Hernández, M.A. (2001) 'Chebyshev's approximation algorithms and applications', Computers Math. Applic., Vol. 41, Nos. 3-4, pp.433-455.

Hernández, M.A. and Salanova, M.A. (1999) 'Sufficient conditions for semilocal convergence of a fourth order multipoint iterative method for solving equations in Banach spaces', Southwest $J$. Pure Appl. Math, Vol. 1, No. 1, pp.29-40.

Kantorovich, L.V. and Akilov, G.P. (1982) Functional Analysis, Pergamon Press, Oxford.

Parhi, S.K. and Gupta, D.K. (2007) 'Recurrence relations for a Newton-like method in Banach spaces', J. Comput. Appl. Math., Vol. 206, No. 2, pp.873-887.

Parhi, S.K. and Gupta, D.K. (2010) 'Semilocal convergence of a Stirling-like method in Banach spaces', Int. J. Comput. Methods, Vol. 7, No. 2, pp.215-228.

Parida, P.K. and Gupta, D.K. (2007) 'A cubic convergent iterative method for enclosing simple roots of nonlinear equations', Appl. Math. Comput., Vol. 187, No. 2, pp.1544-1551.

Ren, H., Wu, Q. and Bi, W. (2009) 'New variants of Jarratt method with sixth-order convergence', Numer. Algorithms, Vol. 52, No. 4, pp.585-603.

Rheinboldt, W.C. (1977) 'An adaptive continuation process for solving systems of nonlinear equations', in Tikhonov, A.N. et al. (Eds.): Mathematical Models and Numerical Methods Pub. 3, No. 19, pp.129-142, Banach Center, Warsaw, Poland.

Traub, J.F. (1964) Iterative Methods for the Solution of Equations, Prentice Hall, Englewood Cliffs, New Jersey, USA.

Wang, X. and Kou, J. (2012a) 'Semilocal convergence of a modified multi-point Jarratt method in Banach spaces under general continuity conditions', Numer. Algorithms, Vol. 60, No. 3, pp.369-390.

Wang, X. and Kou, J. (2012b) 'Semilocal convergence of a class of modified super-Halley methods in Banach spaces', J. Optim. Theory. Appl., Vol. 153, No. 3, pp.779-793.

Wang, X., Kou, J. and Gu, C. (2011) 'Semilocal convergence of a sixth-order Jarratt method in Banach spaces', Numer. Algorithms, Vol. 57, No. 4, pp.441-456.

Wang, X., Kou, J. and Li, Y. (2009) 'Modified Jarratt method with sixth order convergence', Appl. Math. Lett., Vol. 22, No. 12, pp.1798-1802.

Ye, X. and Li, C. (2006) 'Convergence of the family of the deformed Euler-Halley iterations under the Hölder condition of the second derivative', J. Comput. Appl. Math., Vol. 194, No. 2, pp.294-308. 
Ye, X., Li, C. and Shen, W. (2007) 'Convergence of the variants of the Chebyshev-Halley iteration family under the Hölder condition of the first derivative', J. Comput. Appl. Math., Vol. 203, No. 1, pp.279-288.

Zhao, Y. and Wu, Q. (2008) 'Newton-Kantorovich theorem for a family of modified Halley's method under Hölder continuity condition in Banach spaces', Appl. Math. Comput., Vol. 202, No. 1, pp.243-251.

Zhu, Y. and Wu, X. (2003) 'A free-derivative iteration method of order three having convergence of both point and interval for nonlinear equations', Appl. Math. Comput., Vol. 137, Nos. 2-3, pp.49-55. 